\title{
Marina Vidal a través del espejo: identidad trans en Una mujer fantástica.
}

\author{
María Toscano Alonso \\ Universidad de Sevilla \\ http://dx.doi.org/10.12795/AdMIRA.2018.01.04
}

\section{RESUMEN}

Los sujetos constituimos nuestra identidad en relación con aquella imagen que emitimos y la que queremos emitir. La única forma en la que podemos observar cómo nos presentamos a la sociedad y de encontrarnos físicamente a nosotros mismos es a través del reflejo. Este objeto ha estado presente de diferentes maneras en nuestra sociedad desde la antigüedad, ya en la mitología encontramos referencias al reflejo y al espejo. Este elemento es recurrente en diversas expresiones artísticas, el cine también ha hecho uso de éste en múltiples ocasiones, uno de los filmes más recientes donde lo hemos encontrado es en Una mujer fantástica. En esta cinta cobra relevancia en relación a la constitución, reafirmación más bien, de la identidad trans. Por ello, hemos observado cómo se han utilizado los espejos en esta película, qué relación tienen con la identidad de la protagonista.

\section{PALABRAS CLAVE}

Identidad trans, identidad, trans, cine, espejo, reflejo, imagen especular.

\begin{abstract}
People build their own identity based on their self image and the image that they want to share. The only way we can observe how we introduce ourselves to the society and how we find ourselves is trough the mirror. This object has been present in some different ways in our society since the antiquity, already in the mythology we found references to the reflect and the mirror. This element is recurrent in various artistic expressions, the cinema has used that many times too, one of the most recent film in which we found it is in A fantastic woman. In this play the mirror is relevant in relation to the constitution, the reaffirmation specifically, of the trans identity. For this reason, we have observed how has been used the mirrors in this movie, what connection has with the identity of the main character.
\end{abstract}

\section{KEYWORDS}

Trans identity, transgender, identity, cinema, mirror, reflexion, specular image. 


\section{Introducción}

Desde la mitología griega, pasando por la pintura, la poesía y llegando hasta la literatura fantástica y el cine más actual, existe un elemento que ha estado presente de manera reiterada: el espejo. En cada forma de expresión se le han otorgado diferentes significados, bien el narcisismo, proveniente del mito de Narciso, ya sea la autoexploración y autoconocimiento, o una forma de bucear en el pasado, el presente y el posible futuro de uno. El uso de este elemento lo podemos ver en varios filmes de Walt Disney Pictures como Blancanieves y los siete enanitos (Hand, Morey, Jackson, Sharpsten, Cottrell y Pearce, 1937), El Rey León (Minkoff y Allers, 1994) o Mulán (Bancroft y Cook, 1998), donde el reflejo tiene diversos significados. De estas diferentes connotaciones que podemos encontrar de la presencia del espejo en cualquier obra, la que nos resulta de interés en esta investigación es, principalmente, la de la constitución de la identidad. Fue Lacan (2003) quien puso de relieve el estadío del espejo, el cual hace referencia al periodo de tiempo en el que los niños comienzan a ser capaces de reconocerse en el espejo.

Uno de los filmes en el que hemos hallado el uso de diversos espejos y en diferentes contextos y situaciones, es Una mujer fantástica (Lelio, 2017), ganador del Oscar a mejor película de habla no inglesa que narra el duelo de Marina Vidal, una mujer trans que se enfrenta a prejuicios, transfobia y violencia física por parte de personas que no aceptan su identidad.

La identidad trans, como cualquier otra, se valida, a menudo, al colocarse el sujeto frente al espejo y plantearse o encontrarse con lo que quiere ver. Los espejos son la única manera en la que las personas podemos observar nuestra propia apariencia física aún con las carencias que este objeto puede presentar. En el caso de las personas trans la importancia del espejo radica en la disforia entre la imagen que estas personas ven reflejada de sí y la que les gustaría ver, ya que, a lo largo de su vida a las personas trans se les ha asignado una identidad al nacer con la que no se sienten representadas ni identificadas, esta identidad lleva consigo algunos elementos físiológicos con los que nacen y otros que se atribuyen según esas características físicas.

Partiendo de esta relación entre la imagen especular y la identidad, queremos conocer cómo se utiliza este elemento en el filme chileno y qué relaciones tiene la presencia de los espejos con la identidad de la protagonista. 


\section{De la importancia del lenguaje y los debates más actuales}

Actualmente, nos encontramos en un momento de efervescencia social y académica de todo lo relativo a la identidad de género y la sexualidad, esto implica una amplia revisión del lenguaje, de los conceptos utilizados para hacer alusión a ello. Lo que aquí nos atañe concretamente son las identidades trans, pensamos que lo más preciso es hablar de personas trans, englobando así a todas estas personas sin hacer distinción en si "la persona se ha operado o el sentido político que atribuye a su identidad de género" (Coll-Planas \& Missé, 2015: 36). Sin embargo, debemos detenernos brevemente en los términos transexualidad y transgeneridad; ya que ambos se utilizan frecuentemente, sobre todo en contextos y textos relativos a la medicina y el derecho.

En el texto de Coll-Planas y Missé (2015), acudimos a un debate conceptual entre los términos transexual y transgénero, nos plantean los conflictos que se dan dentro de la comunidad trans acerca de los mismos. Este debate da muestra de la dificultad que encontramos a la hora de establecer categorías identitarias ya que "resulta[n] ambivalente[s], pues estas oprimen al sujeto y, al mismo tiempo, le dan vida" (2015: 38), además, como comparten los autores con ideas de Foucault, Weeks y Butler, las categorías se construyen en un escenario de relaciones de poder y no describen a los sujetos sino que son estas categorías las que construyen la subjetividad de aquellos a quienes designan (Íbid.). Finalmente, en cuanto a las categorías identitarias, los autores mencionan que éstas implican que los individuos sientan la necesidad de identificarse con una o varias y de ser reconocidos socialmente por estas, lo cual resulta limitante para aquellas personas que no se sienten identificadas por ninguna y el conflicto social que les produce que el resto de la sociedad no pueda clasificarlas categóricamente.

Una vez planteados los contrapuntos de las categorías identitarias, nos adentramos en los términos concretos: transexualidad y transgénero. En los años 50, David Cauldwell introduce el término transexual para referirse a las personas que se sienten identificadas con el sexo opuesto a aquel asignado al nacer según sus genitales y características biológicas y desean realizar una modificación en su cuerpo para que se corresponda con su sexo sentido, así como modificación de nombre y género en sus documentos de identidad y en su trato con la sociedad; el término fue posteriormente popularizado por Harry Bejamin y es en los 70 cuando se sustituye travestido por transexual en el discurso médico debido a la aceptación de la reasignación mediante cirugía (Coll-Planas \& Missé, 2015: 39). 
Coll-Planas y Missé concluyen exponiendo las dos posiciones diferentes que han detectado: por un lado, la posición de las personas transexuales y por otro la de las personas transgénero. En el discurso transexual, se establece como prioritaria la «necesidad» de realizar la transición, entendiendo que la motivación para una reasignación mediante cirugía es una determinación biológica, inmodificable y, por lo tanto, no elegida. En el discurso transgénero, aquello que se establece como prioritario es liberarse de las presiones de género a través de la crítica al modelo binarista y a la reproducción de los roles de género normativos (2015: 48).

Finalmente, los autores observan que las personas transexuales en muchas ocasiones se ciñen e identifican con el discurso médico, por su parte, las personas transgénero excluyen a las personas transexuales por el deseo de operarse y, en consecuencia, normalizar su cuerpo dentro de lo establecido como femenino o masculino y no salirse de los binarismos impuestos, y se opone al discurso médico. Sin embargo, "puede acabar reproduciendo las lógicas de exclusión que reprocha a la patologización de la transexualidad, al establecer una jerarquía entre personas críticas y personas reproductoras del género normativo" (Coll-Planas \& Missé, 2015: 49). Los autores nos hacen partícipes aquí de la delicada y dificultosa situación en la que se encuentran actualmente las categorías y los colectivos, así como las decisiones tomadas en relación a sus cuerpos, por lo que es preciso entender en el contexto que nos encontramos al hablar acerca de identidades y las diversas posiciones que existen, donde no existe aún consenso. También cabe señalar que, aunque exista este debate, no todas las personas trans critican las decisiones de las otras en lo relativo a establecerse o no dentro de los cánones del sexo/género.

No podemos olvidar que las categorías género y sexo, al igual que las anteriormente comentadas, son categorías creadas y que como consecuencia establecen unos estándares y unos límites a aquello que no se encuentra dentro del cerco que suponen estos términos. Cada vez más, existen personas que se sitúan de manera voluntaria fuera del género; personas agénero o no binarias. Así como existen otras que ven el género como algo mutable, cambiante, las denominadas género fluido.

Amplio es el debate sobre el género y la naturaleza biológica o cultural de éste en relación al sexo (cuerpo). Durante un largo período no se había puesto en duda si el género era o no biológico, puesto que se daba por supuesto que sí. Por lo tanto, la idea de que el sexo llevaba consigo un género y, por consiguiente, unos comportamientos concretos, estuvo muy arraigada hasta que la antropología abriese el "debate sobre qué es lo determinante en el comportamiento 
humano, si los aspectos biológicos o los socioculturales" (Lamas, 2013: 97). Es decir, una persona llega a ser mujer u hombre mediante la repetición de comportamientos que se le presuponen partiendo de los estereotipos y roles asignados a cada género, la performatividad idea introducida por Judith Butler (2007) - viene a afirmar esta idea del género como repetición e imitación. Este planteamiento de que la identidad se crea y no se nace con ella es compartida por numerosos estudiosos y estudiosas de género, Herrera afirma que "a través de la educación y la socialización aprendemos a ser hombre o ser mujer" (Herrera, 2011: 9) y todo aquello que supone una marca identitaria en nuestra vida, desde nuestra profesión hasta nuestras creencias, entre otros aspectos, está determinado "por estos condicionamientos de género que parecen invisibles porque están asumidos como naturales" (Íbid.).

Existe mayor conciencia y numerosos estudios sobre el género, su origen y su perpetuación, pero son más escasos aquellos que ponen en duda el sexo, término que, como afirmábamos anteriormente, resulta limitante para muchas personas que no se enmarcan dentro de lo que uno de los dos sexos aceptados y propagados asientan. Como apunta Shrage, sexo y género no son iguales pero ambos son productos de una construcción social (2009: 21).

La mayor prueba de la restricción y del origen creado del sexo es la intersexualidad. En Cuerpos Sexuados (Fausto-Sterling, 2006), somos partícipes de una amplia reflexión acerca de la medicina y la in-operatividad de la misma en sendos aspectos ya que, como apunta la autora, "nuestra concepción del género afecta al conocimiento sobre el sexo producido por los científicos en primera instancia" (2006: 17), que niegan la existencia de cuerpos que no se pueden clasificar como femeninos o masculinos y, por lo tanto, la realidad de que "entre un 1 y un 4\% de la población mundial podría ser intersexual" (Greenberg, 1999: 267). La ciencia, en lugar de tomar parte y demostrar de forma científica la existencia de diversos cuerpos y, por lo tanto, el carácter construido de los sexos, toma la posición de cambiar los cuerpos que no se corresponden con la dualidad y perpetuar la creencia de que sólo existen dos sexos posibles.

Nos encontramos ante la imposición de un binarismo sexual que excluye a muchas personas y se rige por afirmaciones que cada vez más están siendo puestas en duda. Algunas personas están tomando parte intentando subvertir las normas de género y sexo impuestas, algunas posicionándose fuera, otras tratando de reapropiarse de éstas y usarlas de la manera en la que puedan integrarse dentro de la sociedad. Sea como fuere, debemos poner de relieve la importancia de las categorías, lo que estas suponen; como apunta Chomsky (2002), el lenguaje 
tiene que ver con el pensamiento, pensamos con palabras, entendemos el mundo mediante las palabras y cuando no entendemos algo porque escapa a nuestros conceptos, inventamos un término con el que designarlo. El lenguaje tiene que ver con la acción en tanto que, como decíamos, reproducimos aquello que los conceptos significan, actuamos en consecuencia a las etiquetas que nos identifican; por ello, nuestras relaciones sociales derivan en esta acción y performance continua de nuestra identidad para poder encajar dentro de unas pautas sociales establecidas, "como seres sociales, las mujeres [y todos los colectivos fuera del cisheteropatriarcado caucásico, añadiríamos] se construyen a partir de los efectos del lenguaje y la representación" (Lauretis, 1992: 29).

\section{Panorama legal y social de las personas trans}

En lo relativo a lo legal y social, las personas trans aún se encuentran con múltiples obstáculos y limitaciones, incluso prohibiciones y penas de muerte debidas a su identidad. Según Transgender Europe, sólo siete países europeos no requieren de un diagnóstico psicológico para poder reconocer la reasignación de género de forma legal en los documentos de identidad, estos países son: Dinamarca, Irlanda, Noruega, Francia, Bélgica, Malta y Grecia (Imagen 1); la situación española al respecto la veremos más adelante. Existen otros países en los que es posible pero no de manera plena, sino cumpliendo diversos requisitos que pueden resultar prohibitivos (Transgender Europe, 2018), "las leyes que expresan cuales son los requisitos para pertenecer a uno $\mathrm{u}$ otro sexo son bastante diferentes, pero persiste en todas el ánimo de mantener y preservar una de las bases sobre la que se sustentan las sociedades occidentales, la distinción única y exclusiva de una forma de ser hombre y otra de ser mujer" (Araneta Zinkunegi, 2012: 155). 


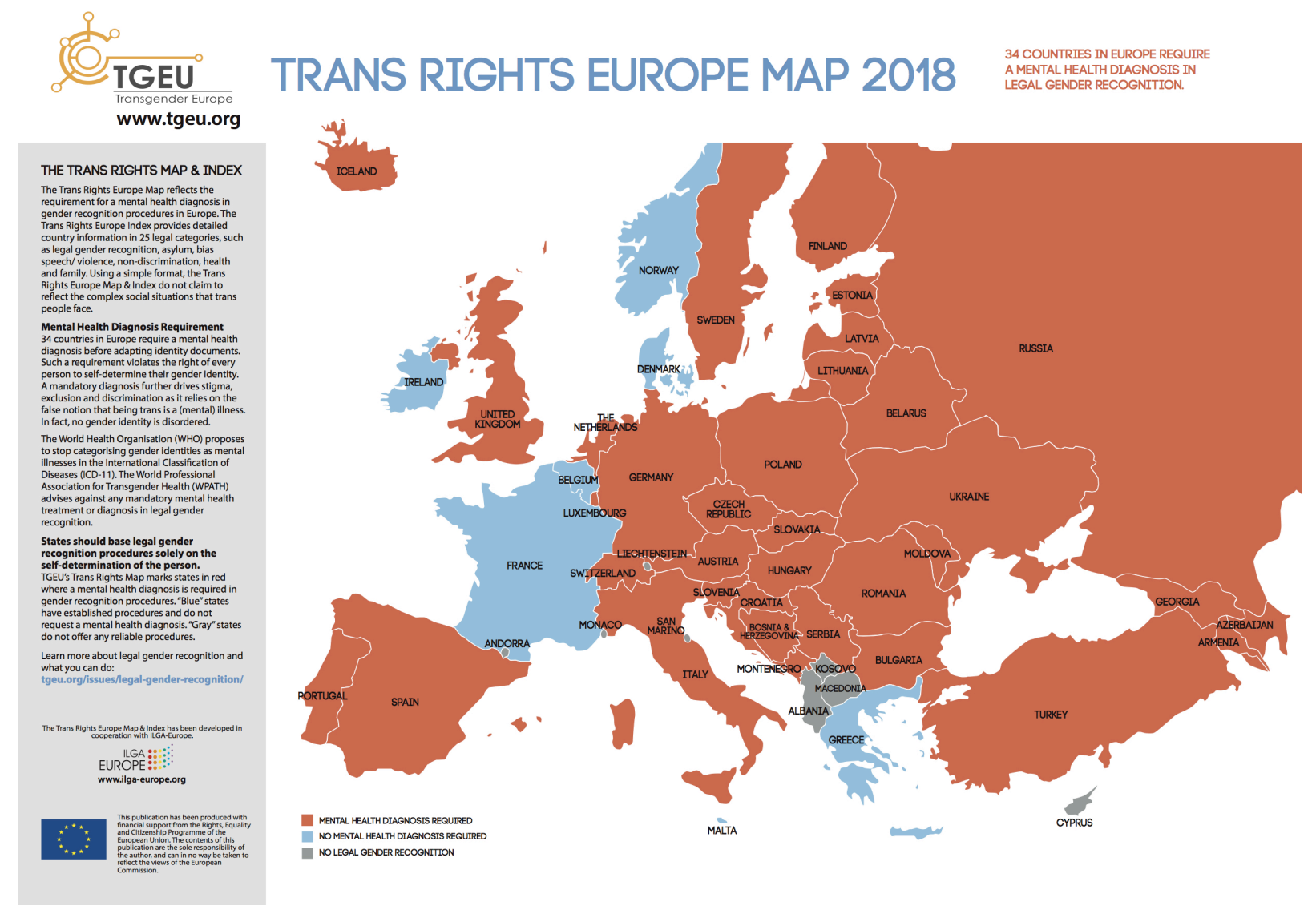

Fuente: Transgender Europe, 2018.

Aunque existen leyes que posibilitan la autodeterminación de género, “estos reconocimientos jurídicos alcanzados por la comunidad LGTB no constituyen per se, inmediata aceptación en el ámbito social” (Mejía \& Almanza, 2011: 80-81). Hallamos en un estudio de 2011 realizado en Estados Unidos que las personas trans sufren acoso, violencia física y sexual en el ámbito académico, además de exclusión a la hora de obtener un empleo, dificultades económicas y limitaciones a la hora de alquilar o comprar una vivienda (Grant, Mottet \& Tanis, 2011: 3) y "en la medida que las personas van pasando de niñes a adultes y van desarrollando su identidad, también va en aumento la discriminación que tienen que enfrentar" (Escoffier, 2017: 2). A nivel mundial, entre 2008 y 2017, 2609 personas trans fueron asesinadas, siendo Brasil el país en el que más asesinatos tránsfobos se produjeron (Transgender Europe's Trans Murder Monitoring, 2017).

En el caso de España, en noviembre de 2017, se aprobó una reforma de la ley de identidad de género, entre las modificaciones que esta reforma propone, estaría una de gran relevancia: la 
eliminación de un diagnóstico médico o psicológico de disforia de género; de igual modo, tampoco se pedirá una acreditación de cirugía, terapia hormonal o tratamientos psicológicos (eldiario.es, 2017) ${ }^{2}$ - esta reforma de Ley aún no ha sido puesta en vigor pasado el mes de junio de 2018.

La consideración de las personas trans como enfermas, si bien ha sido un largo proceso de construcción socio-histórica de identidades abyectas, se produce, oficialmente, en el mismo momento en el cual la orientación homosexual desaparece, para incluir la realidad trans en los manuales internacionales de enfermedades más importantes: El Manual Diagnóstico y Estadístico de trastornos Mentales (DSM), publicado por la Asociación de Psiquiatría Norteamericana (APA), y el Catálogo Internacional de Enfermedades y otros problemas de salud (CIE) de la Organización Mundial de la Salud (OMS). (Araneta Zinkunegi, 2012: 145).

Según el diario digital eldiario.es, en 2017, la última actualización del DSM (V) ha modificado su contenido, eliminando el uso de trastorno de identidad género para pasar a hablar de disforia de género. Por su parte, la OMS "ha hecho pública la eliminación de todas las categorías diagnósticas que afectan de una u otra manera a las personas trans, incluyendo el "trastorno de identidad de género", entre otras" (eldiario.es, 2017)³ , que según se anunciaba estaría vigente a partir de mayo de 2018; ha sido el 18 de junio del mismo año cuando se ha confirmado que la OMS, en la actualización de la CIE - será en la CIE-11-, no incluirá a la personas trans como enfermas mentales sino que estarán en el apartado de "condiciones relativas a la salud sexual". Esta nueva clasificación no entrará en vigor hasta 2022 (eldiario.es, 2018) $^{4}$ por lo que hasta entonces se continuará perpetuando la patologización de estas personas a las que aún la sociedad margina, agrede y excluye (Araneta Zinkunegi, 2012: 148).

Por otro lado, debemos ahondar brevemente en la situación chilena ya que el filme que vamos a analizar está circunscrito a esta nacionalidad. La Ley de Identidad de Género se encuentra aún en proceso de establecerse en el país Latinoamericano, aunque “desde el año 2013 se encuentra en primer trámite constitucional un proyecto de ley que busca regular el derecho a la identidad de género, el acceso a terapias hormonales e intervenciones quirúrgicas, y el cambio de nombre y sexo en los documentos legales" (Valdés, 2016: 17). Actualmente esta ley se encuentra en proceso de aprobación, por el momento se utiliza la ley 17.344, de 1970, que regula el cambio de nombre y apellidos, no obstante, según Valdés, se han adoptado tres soluciones jurisprudenciales: (1) Se concede el cambio nominal y de sexo legal a personas trans sin que se 
hayan sometido a cirugía; (2) se concede el cambio nominal pero no de sexo a las personas trans que no han pasado por procesos quirúrgicos; (3) no se le concede ninguno de los dos cambios si no ha habido intervención mediante cirugía. De estas tres, la primera se aplica de manera poco frecuente y la segunda ha sido prácticamente desechada por la jurisprudencia, por lo que la que se aplica de manera más común es la tercera, que dificulta la modificación de nombre y documento a las personas que decidan no someterse a ningún tratamiento ni operación para adaptarse a la normatividad física impuesta (Íbid.: 6).

Es preciso subrayar un suceso relativo a la actriz Daniela Vega que pese a estar viajando por todo el mundo llevando a diferentes rincones del planeta el filme que protagoniza, no se le permite cambiar su nombre y su sexo en sus documentos de identidad (Emol, 2018) ${ }^{5}$. Tras esta noticia el gobierno chileno afirmó que aceleraría el proceso para que entre en vigor la Ley de Identidad de Género pero actualmente no se ha hecho efectiva. Por su parte, el mismo medio publica la opinión de la actriz, que considera que el filme ha cambiado el pensamiento de los chilenos $^{6}$.

\section{Panorama audiovisual}

El colectivo LGBT ha encontrado, en ocasiones, en el cine un medio a través del cual reivindicar y poner en valor sus diversas experiencias y realidades, sin embargo, también ha sido un colectivo que se ha visto ridiculizado, estereotipado e incluso insultado en numerosas ocasiones en la gran pantalla. Estas representaciones, mayoritariamente las de personas homosexuales, "han acompañado a la cinematografía desde sus inicios, ya sea de forma positiva o negativa, central o secundariamente, y por medio de ella ha reflejado la respuesta de diversas épocas y sociedades ante su presencia” (Chaparro \& Estefan, 2011: 58). Quizá por este último motivo, en las producciones más actuales, vemos un cambio de perspectiva con respecto a las representaciones de gays, lesbianas, bisexuales y trans.

No obstante, el cine se ha tomado sus reservas e incluso censuró durante años la representación de la homosexualidad, para ello los creadores buscaron la manera de introducirla mediante metáforas y ambigüedades. En el contexto estadounidense encontramos el Código Hays, que puso restricciones a aquello que podía ser mostrado en los filmes desde 1934 hasta 1967, prohibiendo una lista de conductas que afectaría a la presencia de la homosexualidad en los mismos (Palencia, 2008: 17-21). "Hays consideraba que el código era una ley que había que cumplir, así que para su perfecta ejecución, la Legión elaboró un sistema de calificación de 
filmes basado en cuatro niveles: A1, sin objeciones para todos los públicos; A2, sin objeciones para adultos y adolescentes; B, en parte objetable; y C, condenada, es decir, prohibida" (Durán Manso, 2016: 63).

La supuesta libertad tras la censura no fue lo que se creía ya que los creadores se autocensuraban debido, en parte, a que la homofobia seguía (y sigue) presente en la sociedad, tanto que por parte de los autores "se teme que hablar de homosexualidad reduzca las posibilidades comerciales de una película, que la convierta en algo que solo tendrá interés para minorías" (Mira, 2016: 9). Si bien es cierto que la libertad de expresión a la hora de llevar a la gran pantalla personajes homosexuales, bisexuales o trans se veía coartada por la situación sociocultural, cada vez más ciudades comienzan a tener festivales de cine gay y lésbico alrededor de los años 70. En la actualidad, existen aproximadamente 150 festivales (Palencia, 2008: 33) en todo el mundo exclusivamente de cine LGBT+, lo cual apunta a su relevancia a la hora de dar visibilidad y poner en circulación dentro del circuito de festivales filmes con representación LGBT+ que por lo general será positiva ya que estos festivales no permitirán un enfoque humillante, degradante o que fomente estereotipos y conductas negativas.

Los personajes gays y lesbianas han sido los más frecuentes, de manera que también los estudios sobre estos personajes son más numerosos. Es imprescindible detenernos en el New Queer Cinema (NQC), surgido en los 90 cuando Ruby Rich (2013) presenció que una "nueva clase de películas y vídeos encontró un hogar y definió una era" (2013: xv), este cine se vio alzado "como parte de una nueva emergencia queer más grande, (...) de un nuevo modo de subjetividad queer definida, sobre todo como Michele Aaron la describe, por una "actitud" compartida de "desafío"” (Juett \& Jones, 2010:3). Sin embargo, todo lo nuevo que aportaba el NQC y lo positivo de este movimiento, encuentra de manera veloz su declive a finales del siglo debido al encasillamiento en los circuitos de cine indie y su no entrada en el cine mainstream (Juett \& Jones, 2010: x).

Actualmente, continuamos hablando de cine queer o de cine LGBT + para referirnos a películas que anteriormente habrían sido NQC. Para ver qué podemos entender por una película queer acudimos a diferentes obras en las que se han planteado esta cuestión (Benshoff \& Griffin, 2005; Rich, 2013; Juett \& Jones, 2010; Schoonover \& Galt, 2016), de ellas, es difícil llegar a una definición común, de todas, en lo que sí coinciden es en la dificultad que supone dar una definición concreta y cerrada. En esta investigación consideramos la relevancia del contenido 
principalmente como elemento indispensable para que un filme sea queer, es por ello que nos vamos a regir por las palabras de Rich, que afirma que debemos considerar como cine queer aquellos trabajos "que pueden reforzar la identidad, visualizar la respetabilidad, combatir la injusticia y reforzar el estatus social” (2013: 41) de todas las identidades queer/LGBT+.

En el caso concreto de los personajes trans es difícil llegar a estudios que aborden la representación que se ha hecho sobre éstos, siempre han estado inmersos de manera transversal en los textos sobre cine queer o LGTB+, sin embargo, no es amplia la bibliografía que se detiene en la representación de las identidades trans.

No podemos olvidar que cada vez son más frecuentes los personajes trans en las nuevas producciones audiovisuales, tanto cinematográficas como televisivas, La chica danesa (Hopper, 2015) o series como Orange Is The New Black (Netflix, 2013 - actualidad), Transparent (Amazon Prime Video, 2014 - actualidad), Sense8 (Netflix, 2015 - 2018) o Pose (FX, 2018 - actualidad), son solo algunas de estas obras. De manera paulatina, se va poniendo en valor la representación de las identidades trans, cada vez más respetuosamente y evitando los estereotipos. Aunque lo cierto es que existen reticencias a las representaciones en las que el personaje que interpreta el filme no es un actor o actriz trans, como ocurrió con la elección del actor Eddie Redmayne para interpretar a Lili Elbe en La chica danesa. No obstante, las series mencionadas sí que incluyen a actrices y actores trans, al igual que lo hace Una mujer fantástica contando con Daniela Vega para protagonizar la cinta. Los motivos que llevan a estas críticas es que, habiendo actrices y actores trans que difícilmente consiguen papeles para interpretar a mujeres y hombres cis, debería dárseles a ellos el poder de interpretar esos personajes. Un ejemplo que se comparte a menudo es el siguiente: si para interpretar a un personaje femenino no se selecciona a un actor hombre y se le disfraza, y se elige a una actriz mujer, ¿por qué para interpretar a un personaje trans sí se selecciona a una persona cis y se la disfraza?

Sea como fuere, viendo el cambio de panorama que se está viviendo respecto a la representación de las identidades trans, podemos pensar que pronto comenzarán a surgir mayor número de estudios sobre estas representaciones así como diferentes perspectivas desde las que abordarlas. 


\section{La construcción de la identidad mediante la imagen especular}

Jaques Lacan (2003) ha sido reconocido como el mayor impulsor de la consideración del espejo a la hora de construir el yo. Partiendo del psicoanálisis freudiano, Lacan sugiere que "el sujeto se constituye a través del espejo, en la imagen, en lo imaginario. Luego, en lo simbólico - en el lenguaje - encontrará sus credenciales, vale decir su lugar, para escapar así de la angustia brutal de los vaivenes de la reflexión. [...] La coherencia que las palabras ofrecen es siempre demasiado frágil y el retorno al espejo - siempre deficitario - es inevitable" (González Requena, 2007: 20).

Al inicio de este texto decía que la única manera que tenemos de acceder a nuestra propia imagen es mediante la imagen especular, es decir, aquella que nos devuelve una superficie reflectante, un espejo. Como apunta González Requena, pese a que los sujetos tenemos otra manera de presentarnos y de encontrarnos a nosotros mismos, mediante el lenguaje, éste, al ser una construcción social creada para dar sentido a lo que vemos puede resultar en ocasiones limitante e incoherente con lo que el sujeto puede percibir mediante el sentido de la vista.

Si Lacan parte de un punto de vista psicoanalítico, encontramos que no es esta la única manera de abordar la identidad y el yo, desde la filosofía, sobre todo desde posiciones más ligadas a la metafísica, también se ha repensado la cuestión identitaria aunque con diferentes connotaciones e intenciones, así como diferentes sujetos ya que, desde las aportaciones filosóficas se aborda no solo el yo sino el nosotros, la humanidad.

En Salcedo (2009), trata de llegar a una definición de identidad, aquí, plasma diferentes visiones filosóficas sobre la identidad del ser, dónde, en primer lugar nos resumen la creencia de Heráclito de que el ser fluye y está en constante cambio, por otra parte, Parménides piensa que el ser es permanente (2009: 32-33). Según expone el autor, Hegel también se posiciona en la condición cambiante de la identidad del ser, éste "se construye en la temporalidad, está inmerso en un continuo hacerse, definiéndose en medio de los acontecimientos propios de la existencia y de la acción. El ser no permanece ajeno al cambio, lleva dentro de sí mismo lo otro que aún no se es" (Salcedo, 2009: 34). Por su parte, Ricoeur incide en dos tipos de identidad, la personal y la narrativa, en cuanto a que la identidad se construye en la medida en la que la transmitimos y la contamos, a través de la narrativa llegamos a conocer la identidad colectiva, la historia; pero también la identidad individual (Íbid,: 37). 
Sin embargo, desde la filosofía no hay un acercamiento a la parte física del individuo en cuanto a la imagen del ser y a cómo ésta supone un elemento relevante en cuanto a la identificación de un sujeto a su expresión. Lacan, cuando plantea el estadio del espejo, afirma que "la forma total del cuerpo, gracias a la cual el sujeto se adelanta en un espejismo a la maduración de su poder, no le es dada sino como Gestalt, es decir en una exterioridad donde sin duda esa forma es mas constituyente que constituida" (2003: 87-88). Dentro de la teoría de Ricoeur sobre la identidad narrativa, podemos considerar que la imagen es parte de la identidad narrativa individual ya que la imagen es relevante a la hora de contarnos a nosotros mismos, de la misma forma que lo es cuando tratamos de acceder a la identidad colectiva y conocer cómo era esta identidad en determinado espacio y tiempo.

Por otro lado, encontramos en el texto de Godoy (2015) una recopilación de ideas de diferentes teóricos de entre los cuales nos resulta subrayable la posición del psicólogo social Kenneth Gergen, éste contempla que "la identidad es una construcción social que tiene lugar en forma permanente. El contexto sociocultural desempeña un rol fundamental en este proceso, en tanto establece los patrones a partir de los cuales las/os sujetas/os se hacen inteligibles frente a la sociedad" (Godoy: 111).

De entre todas estas ideas debemos tener en cuenta diversos aspectos. Tal y como apunta Hegel, la identidad fluye, es por ello que las personas trans nacen y con un género asignado, con una genitalidad que tiende a definirles, al igual que al resto de la sociedad, como hombres o mujeres. A estas personas se les impone una identidad desde que nacen y es una vez que son capaces de utilizar el lenguaje, del que hablaba Lacan, cuando exponen su disconformidad con esa identidad impuesta. Antes de esto, se da una relación con el espejo, es en este enfrentamiento de las personas trans con el espejo cuando pueden verse en una pseudo totalidad y comprobar que lo que ven, la identidad que se les impone en lo relativo a la vestimenta, el peinado o los accesorios como los pendientes - marcadores del género - según su genitalidad, no es lo que son. Entonces, comienza a darse una transformación mediante la cual, a través de lo físico, de la forma, hacen visible la identidad sentida, de manera que se narran, no solo con las palabras al expresar su identidad sino también mediante la imagen.

Pero, como apunta Godoy cuando menciona las ideas de Gergen, y llegando al debate existente entre personas transexuales y transgénero que exponíamos anteriormente, los sujetos trans en muchas ocasiones tratan de hacerse intelegibles a la sociedad - o se ven obligados -, 
exceptuando los casos en los que tratan de romper con el binomio hombre/mujer, femenino/masculino y expresan su identidad saliendo de una normatividad que pueda ser leída, transcendiendo, de manera visual, las dos representaciones físicas del género.

\section{Metodología}

Para esta investigación, vamos a valernos de la Teoría Narrativa, llevaremos a cabo un análisis cualitativo interpretativo. Como encontramos en Stam, Borgoyne y Fitterman-Lewis (1999), "el análisis narrativo del cine es la rama más reciente de la investigación semiótica al emerger de las iniciativas críticas que redefinieron la teoría fílmica en los años setenta", este tipo de análisis "persigue desentrañar las relaciones aparentemente «motivadas» y «naturales» entre el significante y el mundo de la historia con el fin de revelar el sistema más profundo de asociaciones culturales y relaciones que se expresan mediante la forma narrativa" (1999: 91).

Es preciso señalar que en el análisis narratológico se produce una interpretación del texto narrativo, "es posible a partir de una descripción («el texto está construido así») atribuirle un significado al texto («el texto significa esto»). Una interpretación no es nunca más que una propuesta («creo que el texto significa esto»). Si una propuesta pretende ser aceptada, debe estar bien fundada («creo sobre la base de los datos presentados que el texto significa esto»)" (Bal, 1985: 17).

A través de la interpretación de las escenas en las que aparezcan espejos o superficies reflectantes, trataremos de aportar nuestra propuesta sobre la importancia de los espejos en cada una de las escenas que aparecen y qué relación tiene el uso de estos con la identidad trans de Marina, la protagonista.

\section{Análisis}

Una mujer fantástica comienza con un plano de las Cataratas del Niágara, seguidamente, se nos presenta a Orlando (Francisco Reyes) en un spa donde, como conocemos posteriormente, se prepara para ir a cenar con Marina (Daniela Vega), su pareja, el día del cumpleaños de ella. En la escena previa a la cena se nos muestran algunos datos sobre ella, dos de ellos son de gran evidencia: Marina es cantante y tiene alrededor de 20 años menos que Orlando. Ambas cosas tendrán relevancia en el desarrollo del filme. 
Después de una cena de festejo en la que Orlando le regala a Marina un viaje a las Cataratas del Niágara - anunciadas previamente -, la pareja se va a una discoteca y luego a casa. Allí, tras mantener relaciones sexuales - en este momento vemos un primer reflejo de Marina, mantienen relaciones apoyados en una cristalera en la que se reflejan levemente y que posteriormente mientras están en la habitación también se aprecia, sin embargo no hay una interacción directa entre el personaje y el reflejo -, vemos que en mitad de la noche Orlando está despierto con malestar. Marina decide llevarlo al hospital, pero durante varios segundos lo deja solo mientras ella coge las llaves del coche. Él, en estado de poca lucidez, se acerca a las escaleras, donde tropieza y cae hacia abajo por el primer tramo de escalones, dejándole esta caída diversas contusiones por el cuerpo. Finalmente, llegan al hospital y tras varios minutos un médico le traslada a Marina la noticia del fallecimiento de su pareja, es a partir de este momento cuando ella comienza a ser puesta en duda, a ser sospechosa e incluso a ser tratada con violencia institucional por su identidad. Desde el momento en el que se conoce la muerte de Orlando, comenzamos a encontrar las alusiones a la identidad trans de Marina de la cual no se había hecho mención previamente.

Es entonces cuando se nos presenta el primer espejo en el que Marina se refleja de manera clara, e interactúa con él, (Imagen 2) del filme. Tras conocer la muerte de Orlando, entra al baño deprisa, se encierra en uno de los cubículos donde están los inodoros, allí se derrumba y comienza a llorar arrodillada en el suelo. Acto seguido, sale del cubículo, se lava la cara y se postra frente al espejo. Podemos entender en esta mirada de Marina a sí misma dos cosas, por un lado, la dureza de la pérdida de Orlando, por otro, esta mirada es una anteposición a lo que va a pasar cuando salga del baño. Se ve a sí misma, ve lo que otros van a ver de sí misma y cómo van a utilizar esa imagen, su identidad, para dañarla, para herir aún más a una persona que acaba de perder a un ser querido. 
Imagen 2.

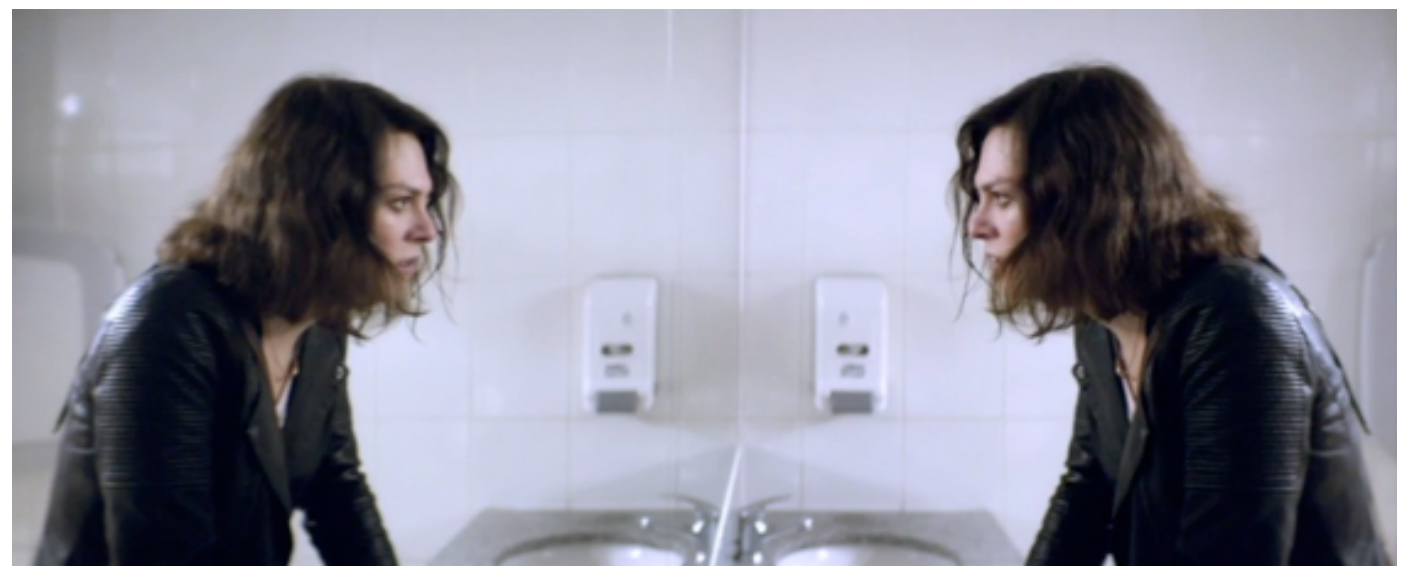

Fotograma del filme Una mujer fantástica.

La obra continúa y Marina sigue teniéndose que enfrentar a más dudas y sospechas hacia ella, pocos minutos después del primero aparece la siguiente escena con espejos (Imagen 3 e Imagen 4), esta vez no es uno, sino alrededor de una decena. Marina se encuentra en el bar en el que trabaja como camarera cuando recibe una llamada, en un plano secuencia comienza a caminar para alejarse a hablar. Cuando descuelga el teléfono, pasa junto a dos espejos, continúa subiendo unas escaleras y finalmente se detiene mientras habla con Sonia, la ex-mujer de Orlando, tras de sí se encuentran varios espejos que, al igual que todos los ojos de investigadores y familiares de Orlando, se encuentran detrás de ella, acechándola y vigilándola. Todas las miradas están sobre ella, que seguidamente, antes de acudir a ver a la comisaria ésta investigará si Marina ha sufrido abuso o violencia por parte de Orlando, no sin antes insinuar que ella podría ser prostituta-, también tiene un espejo observándola al fondo (Imagen $5)$.

\section{Imagen 3.}

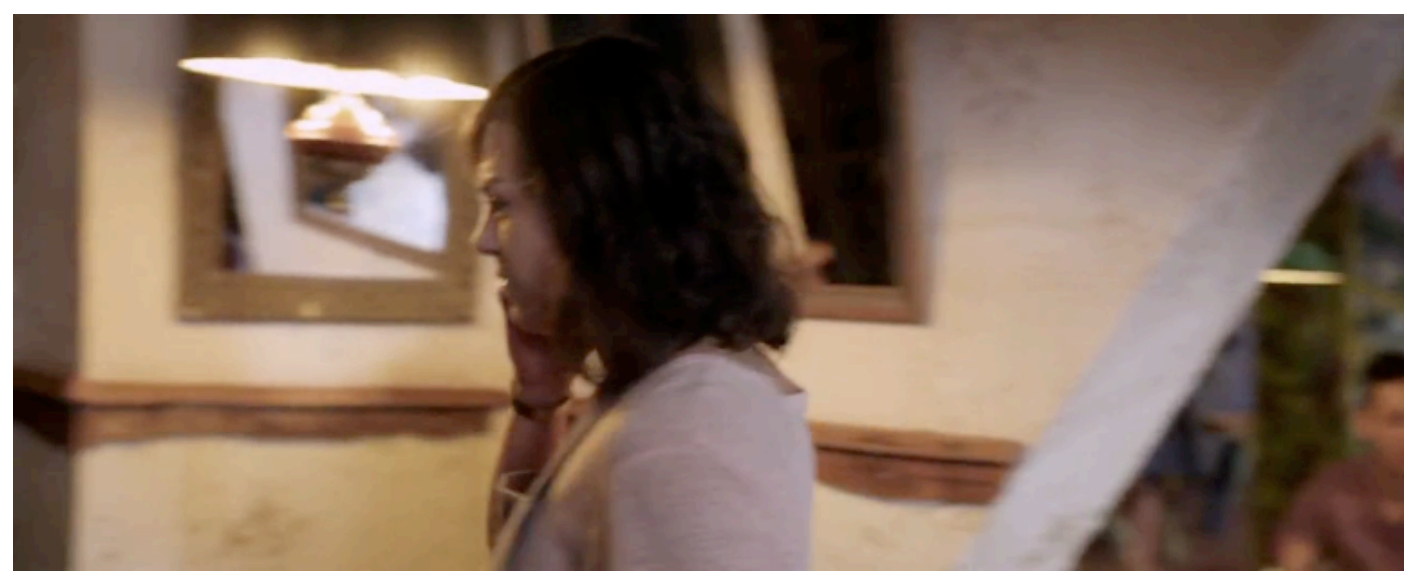

Fotograma del filme Una mujer fantástica. 
Imagen 4.

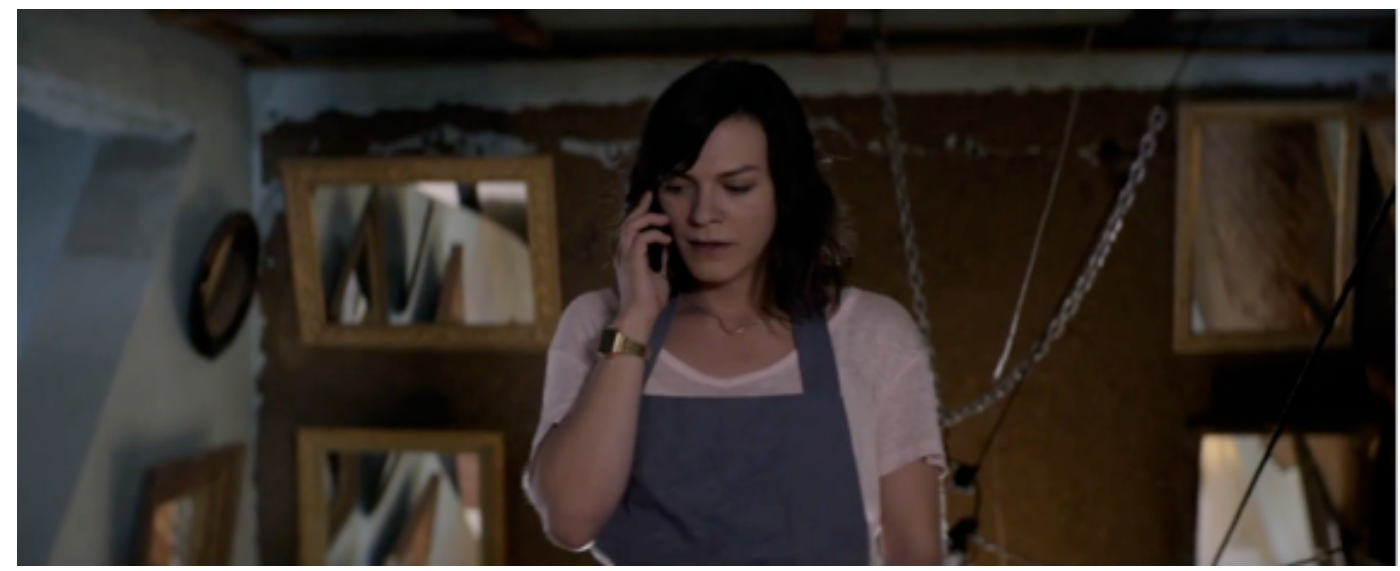

Fotograma del filme Una mujer fantástica.

Imagen 5.

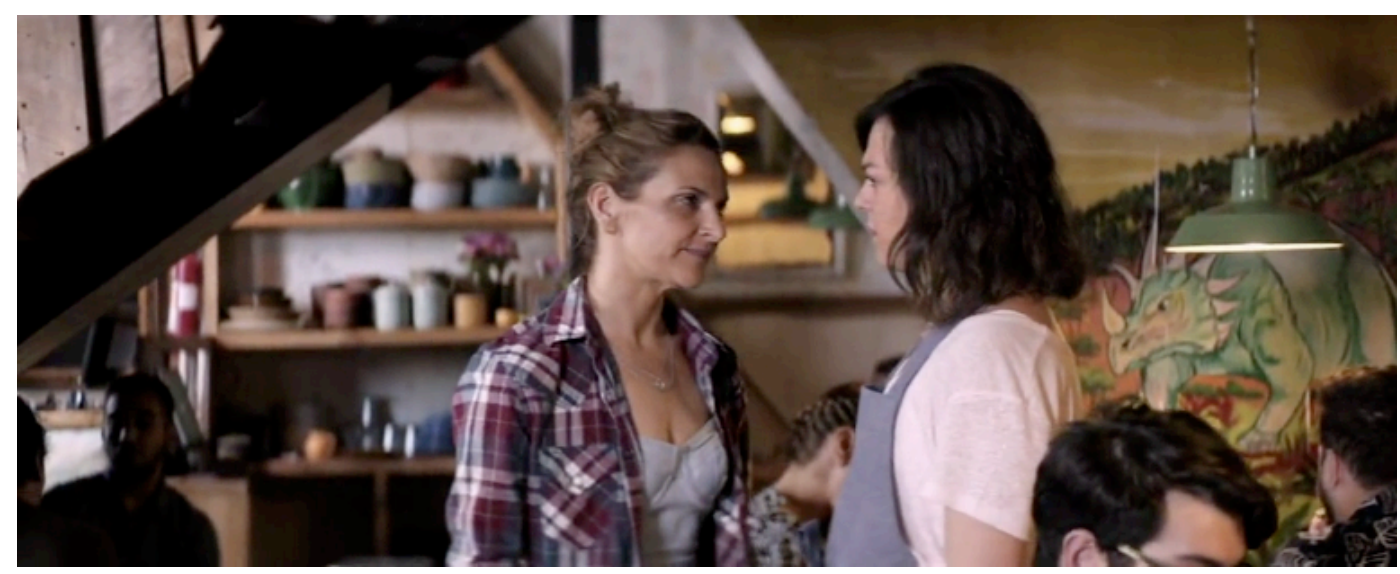

Fotograma del filme Una mujer fantástica.

Quizá en los siguientes espejos que se nos presentan sea donde mayor relación con la identidad hallamos, si en el primero era una breve mirada hacia adelante y en el segundo una muestra de la vigilancia a la que Marina se encuentra sometida, el tercer (Imagen 6) y cuarto (Imagen 7) espejo son un contraste entre la humillación y la puesta en valor de sí del personaje. El sujeto, Marina, en el primer plano acaba de ser víctima de la conducta violenta de Bruno, el hijo de Orlando, cuya transfobia es visible desde el primer momento, diciéndole cosas como si se ha operado o que no entiende qué es, quiere echar a Marina de la casa de su padre, donde ella se acaba de mudar, y también quiere arrebatarle a Diabla, la perra de Orlando que le había dejado a ella. Cuando Bruno se marcha, después de este primer encuentro que finaliza cuando él la agarra y empuja contra la pared diciéndole a escasos centímetros de su rostro: “increíble, mi papá estaba loco"; ella se queda parada mirando su imagen reflejada en un cuadro durante un 
par de segundos. Acto seguido aparece frente al espejo de la habitación, se mira y comprueba cómo le queda el vestido que lleva puesto. Podemos pensar que incluso en la primera imagen puede llegar a dudar por un momento si Bruno tiene razón para - correspondiéndose esta leve duda con la brevedad de la imagen -, al contrastar con la siguiente, reafirmar su identidad con un plano más pausado en el que lleva un vestido y maquillaje, al contrario que en el anterior donde su aspecto es más desaliñado. Siendo la segunda escena una muestra más fiel a quien ella siente que es y cómo quiere mostrarse para sí y para el resto.

Imagen 6.

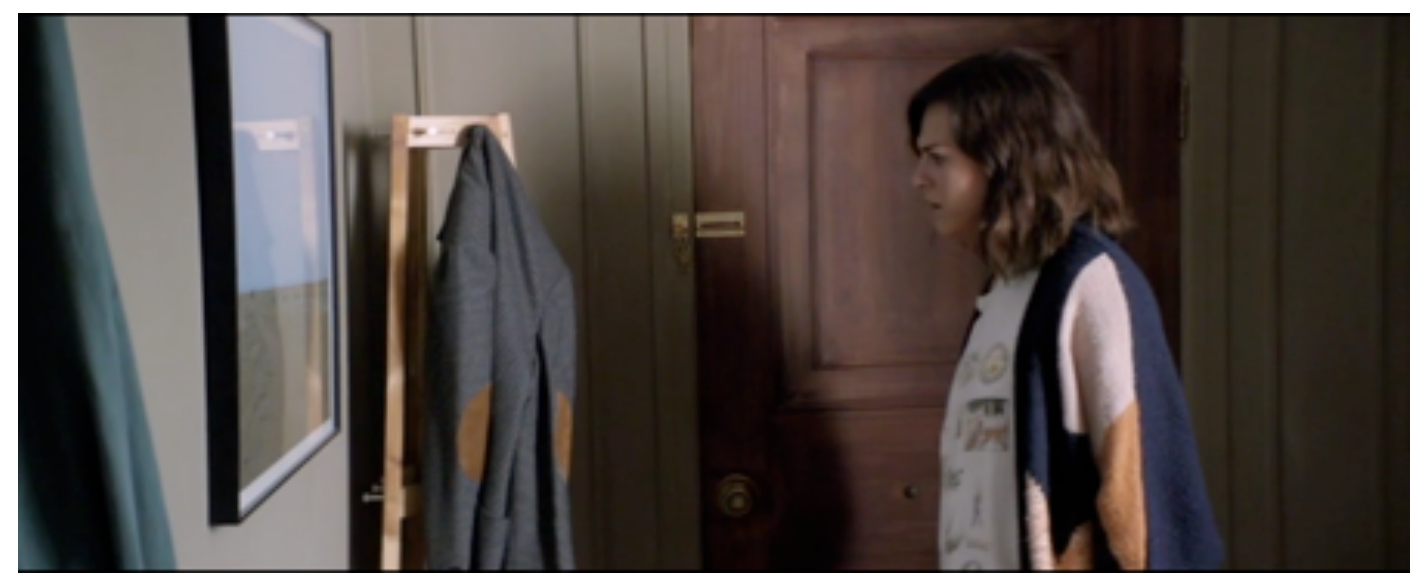

Fotograma del filme Una mujer fantástica.

Imagen 7.

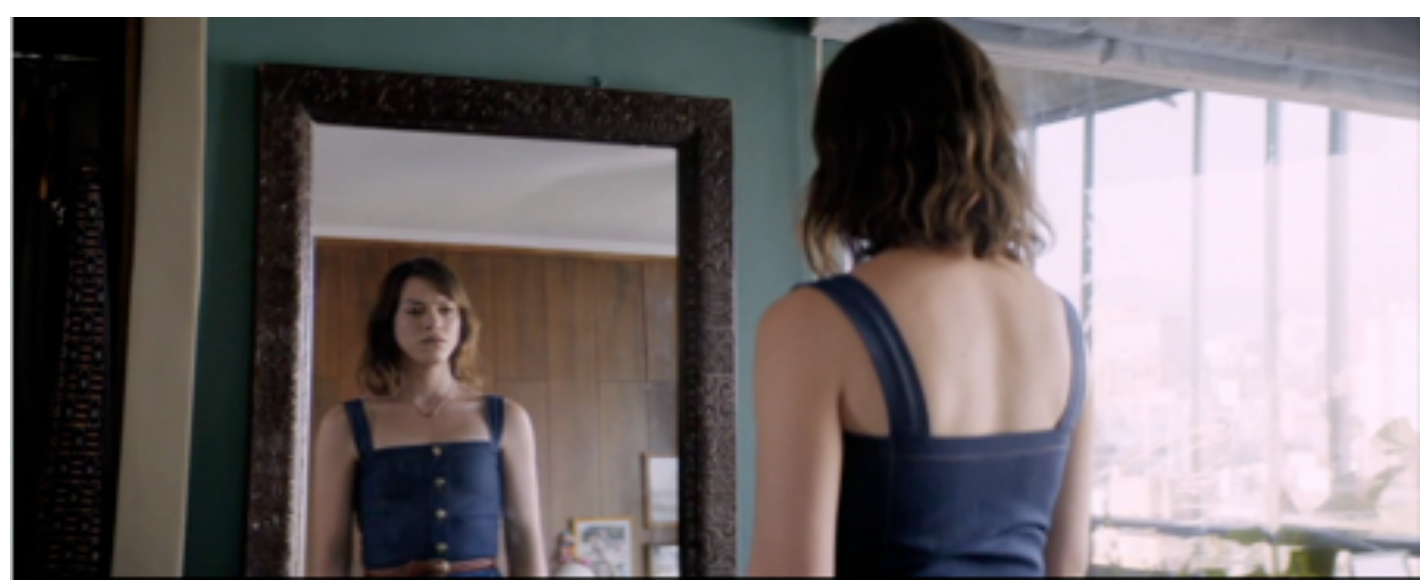

Fotograma del filme Una mujer fantástica.

La siguiente vez que observamos un espejo no es el reflejo de Marina el que aparece, sino el de Orlando (Imagen 8) al que varias escenas antes también habíamos visto en el reflejo de las gafas de sol de Marina (Imagen 9), como una mirada al pasado, al recuerdo de su pareja 
difunta, el apoyo que ha perdido y motivo por el cual tiene que enfrentarse a diversas situaciones de violencia, de humillación, de puesta en duda. Tras esta visión de Orlando - la de la Imagen 8 -, ella se dirige al lugar de trabajo de la ex-mujer de él, durante el viaje en coche Marina escucha la canción (You make me feel like) A natural woman, de Aretha Franklin, esto podría ser una especie de canto, de declaración a su difunto novio, contándole cómo él hacía que se sintiese: You make me feel so good inside and I just want to be close to you, you make me feel so alive ${ }^{1}$; ya que ahora se ha dado la vuelta la situación y no hacen más que recordarle que cuando nació se le asignó, se le impuso, un género con el que ella no se siente identificada, algo que nadie acepta como aceptaba, respetaba y amaba Orlando.

Es preciso señalar que, la primera vez que aparece el reflejo de Orlando, seguidamente ella comienza a cantar, en la segunda ocasión ocurre de manera inversa, ella canta con los ojos cerrados mientras el coche pasa por el túnel de lavado y es entonces cuando ve a Orlando de nuevo. La asociación música/Orlando es recurrente a lo largo de la cinta. La primera vez que vemos a Marina está cantando con una banda en un bar, ella tiene una apariencia feliz - es cuando más feliz la vemos a lo largo del filme - y sonríe a Orlando, que la mira, escucha e incluso canta en voz baja parte de la canción. Luego, además de las veces que Orlando se le aparece, encontramos una escena en la que acude a su profesor de canto, quizá uno de los instantes en los que la protagonista está más baja de ánimo y busca algún lugar en el que sentirse querida. Finalmente, el culmen del filme la muestra a ella sobre un escenario cantando, cuando parece haber superado la pérdida de su pareja. Por lo tanto, es lícito entrelazar a Orlando con la música, bien porque cuando aparece la música también lo hace él, como por la superación de la perdida que se muestra a través del logro de cantar en un teatro para muchas personas.

Justo después de la escena en la que Marina escucha la canción, acude a entregarle el coche de Orlando a Sonia la ex-mujer de él, la cual insulta y violenta verbalmente a Marina, diciéndole que en ella ve pura perversión, que cuando la ve, ve una quimera. Por lo que, como decíamos, este espejo representa el anhelo que Marina siente y se contrasta con el trato que recibe por parte de la ex-mujer de Orlando, entre otros personajes. Tras finalizar la conversación en el parking con Sonia, suben en el ascensor donde, Marina, le da la espalda al espejo (Imagen 10), podríamos entender que, aún siendo por la posición en la que se encuentra al entrar, esta imagen podría significar la negación como persona a la que acaba de ser sometida por parte de 
Sonia, que justo después de salir del ascensor trata de negarle también el derecho a despedirse de Orlando y de darle dinero, llamándola Daniel.

Imagen 8 .

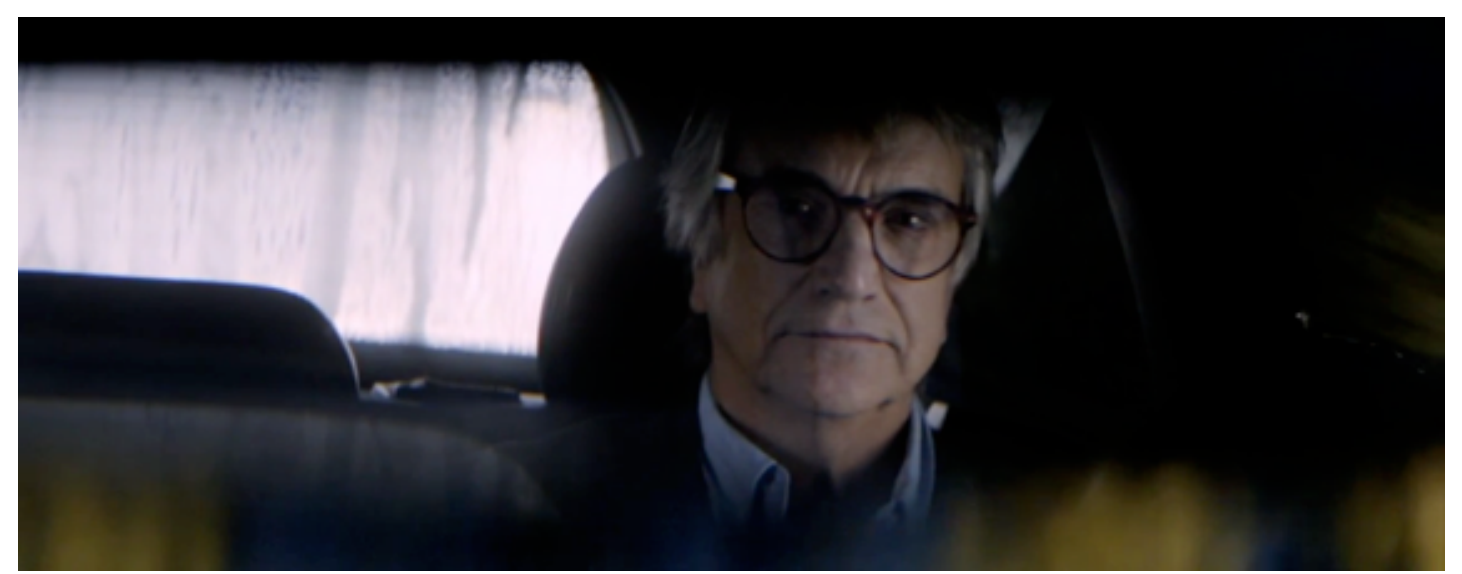

Fotograma del filme Una mujer fantástica.

Imagen 9.

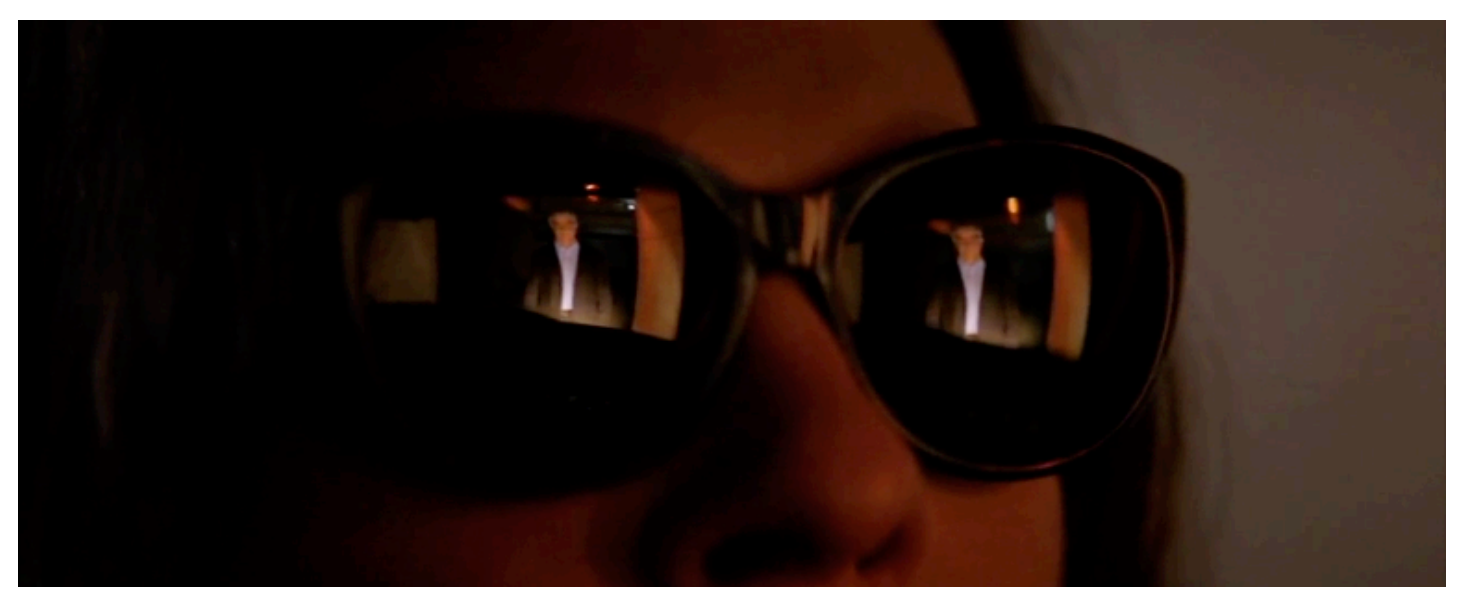

Fotograma del filme Una mujer fantástica. 


\section{Imagen 10.}

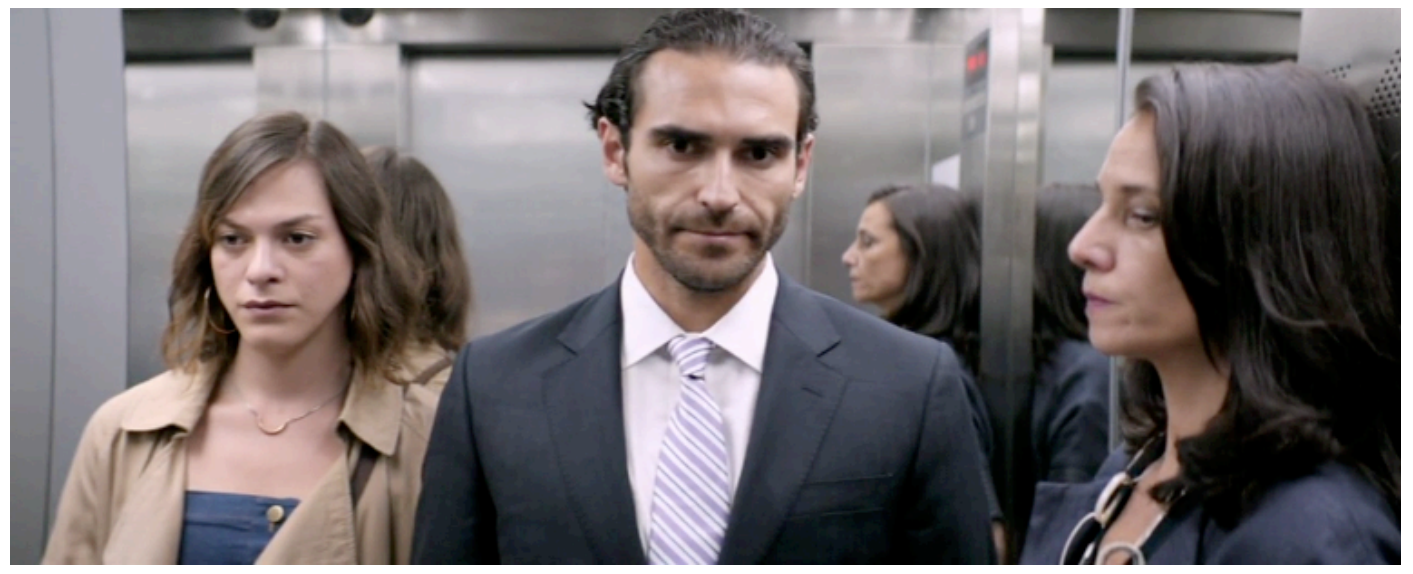

Fotograma del filme Una mujer fantástica.

La siguiente escena en la que vemos a Marina enfrentarse a su reflejo es probablemente la que mayor dureza encierra de todo el filme. Ella acude al velatorio de Orlando, al que previamente la familia ha intentado disuadirla de ir, el hermano de Orlando, Gabo, único miembro de la familia que parece aceptar a Marina, le ofrece parte de las cenizas para que no acuda y así evitar problemas, pero esto no hace más que aumentar sus ganas de ir. Marina asiste finalmente al velatorio tras llegar a la casa de Orlando y descubrir que Bruno se ha instalado allí. Cuando entra, Gabo se queda perplejo y Sonia se levanta y grita, provocando una situación que podría haberse evitado si tan solo hubiese dejado que Marina se sentase sin decir nada ni parar la ceremonia. Incluso una señora que se encuentra allí, le dice que se vaya, que no tiene respeto por el dolor ajeno, ¿y el de ella? Nadie a lo largo del filme parece darle importancia al dolor que está sufriendo ella, que no solo siente la pérdida de un ser querido, sino también la discriminación y violencia de todo tipo a la que se ve sometida por instituciones y familiares de Orlando, quizá exceptuando a Gabo, que parece entender a Marina pero no termina de posicionarse a su favor ni de ayudarla, muestra de la posición que toman muchas personas ante las injusticias aún estando en contra de éstas.

Marina sale del velatorio y se marcha, por el camino, el hijo de Orlando junto a dos familiares más le gritan desde el coche, ella les contesta y sigue hacia adelante, pero ellos deciden bajarse del coche, agarrarla y meterla dentro de éste en contra de su voluntad. Una vez dentro del coche, la insultan y le rodean la cara con cinta adhesiva. Luego, la dejan tirada en un sitio de edificios en ruinas donde aparentemente hay prostitutas y le dicen "que te quede claro" dándole a entender que es el lugar en el que debe estar. Marina, una vez fuera del coche y algo aturdida, 
camina para salir de ese lugar cuando encuentra un coche aparcado. Se detiene a mirar su reflejo (Imagen 11) para comprobar el resultado de la violencia que acaba de sufrir al observar su rostro desfigurado por la cinta. Completamente rota, Marina entra en una discoteca donde se deja llevar despojada de cualquier atisbo de ánimo y esperanza, es allí donde vuelve a ver a Orlando, entre la multitud.

Imagen 11.

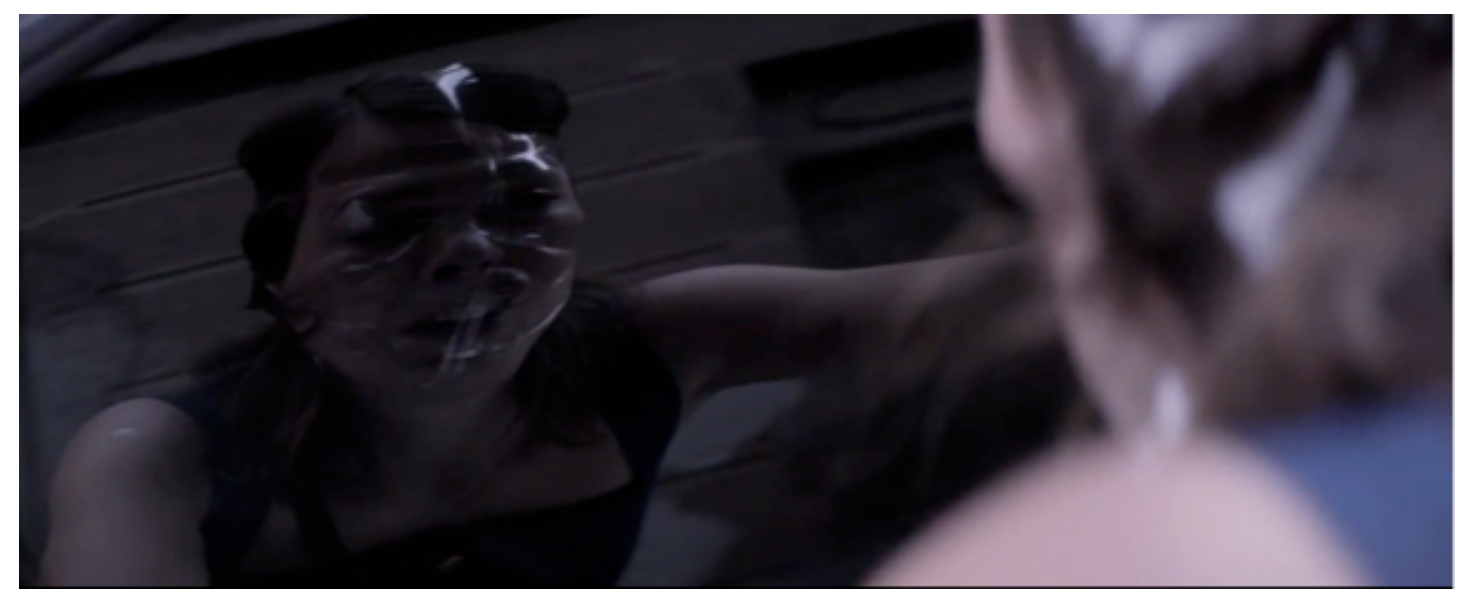

Fotograma del filme Una mujer fantástica.

A continuación, tras decidir no acudir a la incineración de Orlando después de haber sufrido la humillación y la violencia por parte de la familia de éste. Marina acude a la peluquería, se hace la manicura y camina hacia el trabajo cuando se cruza con un par de hombres que trasladan un espejo, de pronto, se encuentra con su imagen de frente (Imagen 12). La imagen que este espejo le devuelve tiene un componente onírico por el movimiento que se produce en su reflejo al estar el espejo en movimiento (Imagen 13). La situación a la que Marina se está teniendo que enfrentar parece una pesadilla, un mal sueño del que quiere despertar. En ese estado de ensoñación, Marina camina y recibe una señal cuando el espejo desaparece y un neón del bar aparece frente a ella, invitándola a entrar.

Justo después, Marina va a descubrir una incógnita que la acompaña durante el filme, de qué es la llave que encuentra en el coche de Orlando. El resultado de este descubrimiento desencadena una reacción determinante por parte de Marina ya que, en la taquilla de la sauna que se abre con dicha llave, no hay nada, está vacía - en el camino hacia la sauna Marina pasa junto a unos espejos pero estos no aportan nada a la narración, como en otras ocasiones. Puede que Marina esperase encontrar algo de Orlando o quizá los billetes de avión perdidos para las Cataratas del 
Niágara, que le darían la oportunidad de huir, sin embargo, la taquilla vacía hacen que cambie de decisión, acude al entierro de Orlando, a recuperar lo que es suyo y a despedirse definitivamente de él.

\section{Imagen 12.}

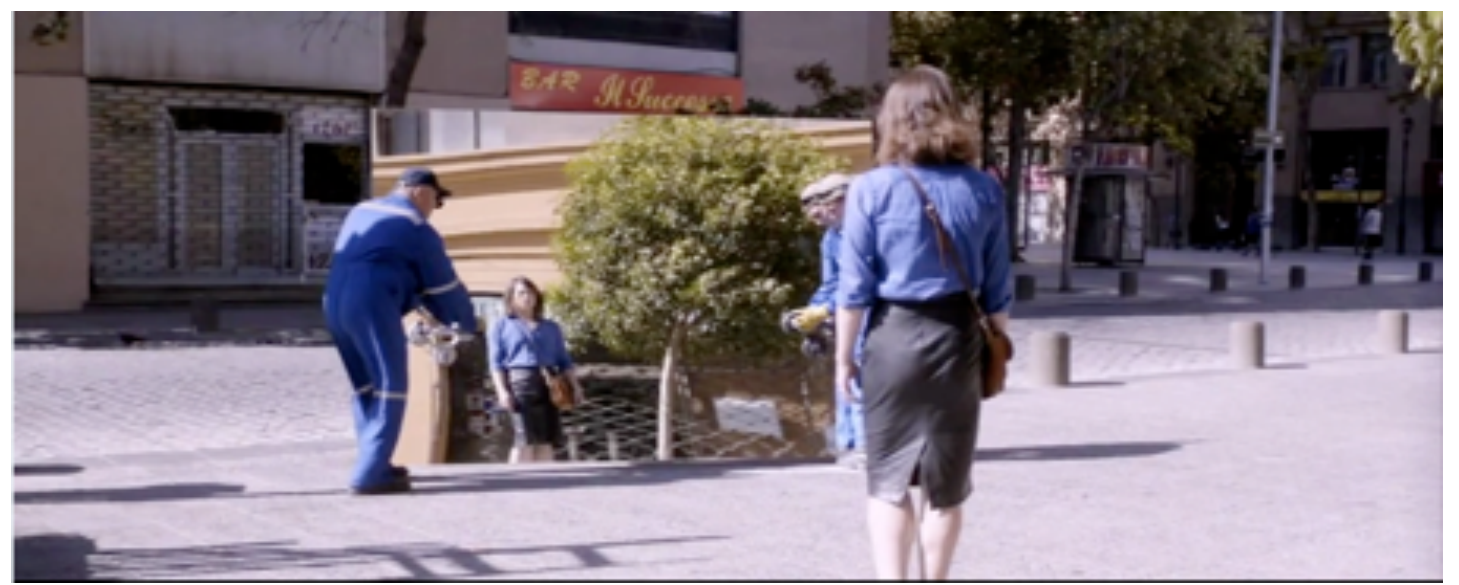

Fotograma del filme Una mujer fantástica.

Imagen 13.

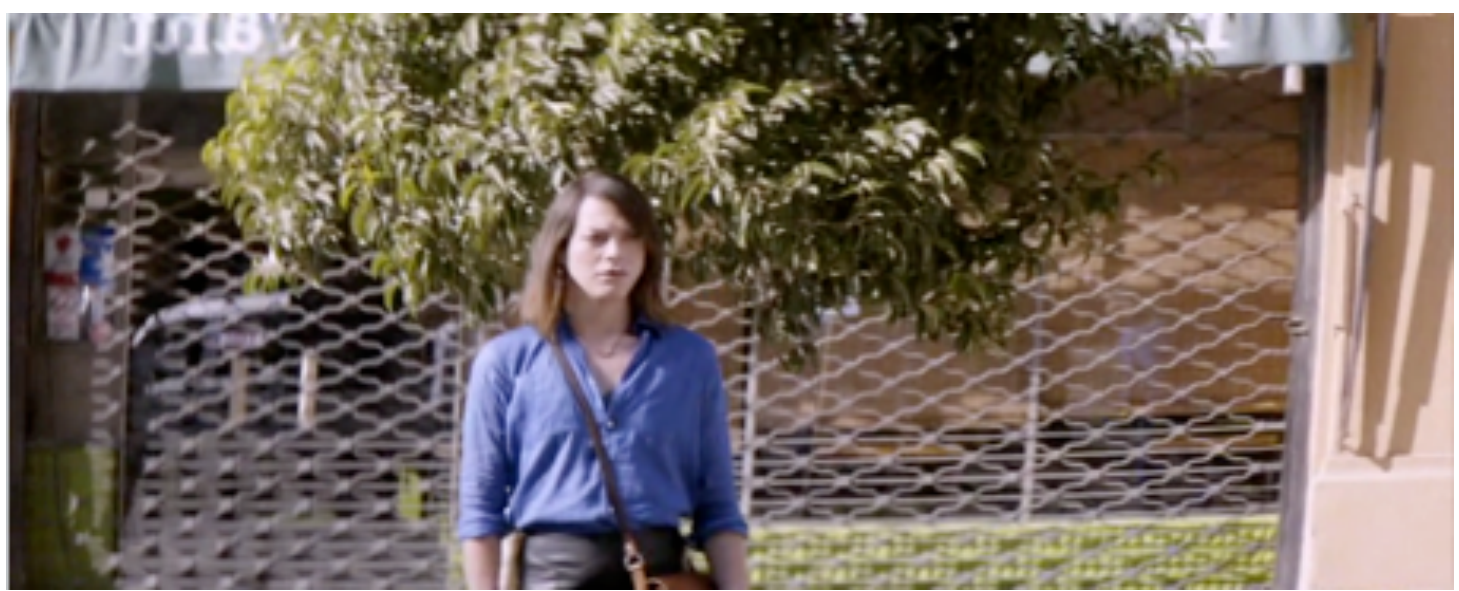

Fotograma del filme Una mujer fantástica.

El final del filme se compone de dos escenas cuyos planos son relevantes y una tercera de transición en la que también hay presencia de grandes espejos. Llegamos al cierre de la cinta, vemos que ha pasado algo de tiempo, Marina ha recuperado a Diabla y ha salido a correr con ella, posteriormente las vemos en un pequeño apartamento donde entendemos que ahora vive Marina. Ella se encuentra tumbada en la cama, desnuda, con un espejo entre sus piernas (Imagen 14). Marina mira directamente su rostro en el espejo que tapa sus genitales, aquí estamos ante el momento más relevante en lo relativo a la identidad trans de la protagonista, a 
lo largo del filme se le pregunta si se ha operado o no sus genitales, este plano habla de la no importancia de la genitalidad para ser quien eres. Marina está mirando a su entrepierna y se está viendo a sí misma, es indiferente lo que hay tras el espejo, lo que importa es lo que ella ve frente a él, se ve a sí misma, una mujer fuerte, valiente, que ha luchado contra el odio y la violencia que ha sufrido por no esconder su identidad, pero lo más importante, se está viendo a sí misma porque, como le dice a su hermana a lo largo del filme: ha sobrevivido.

Imagen 14.

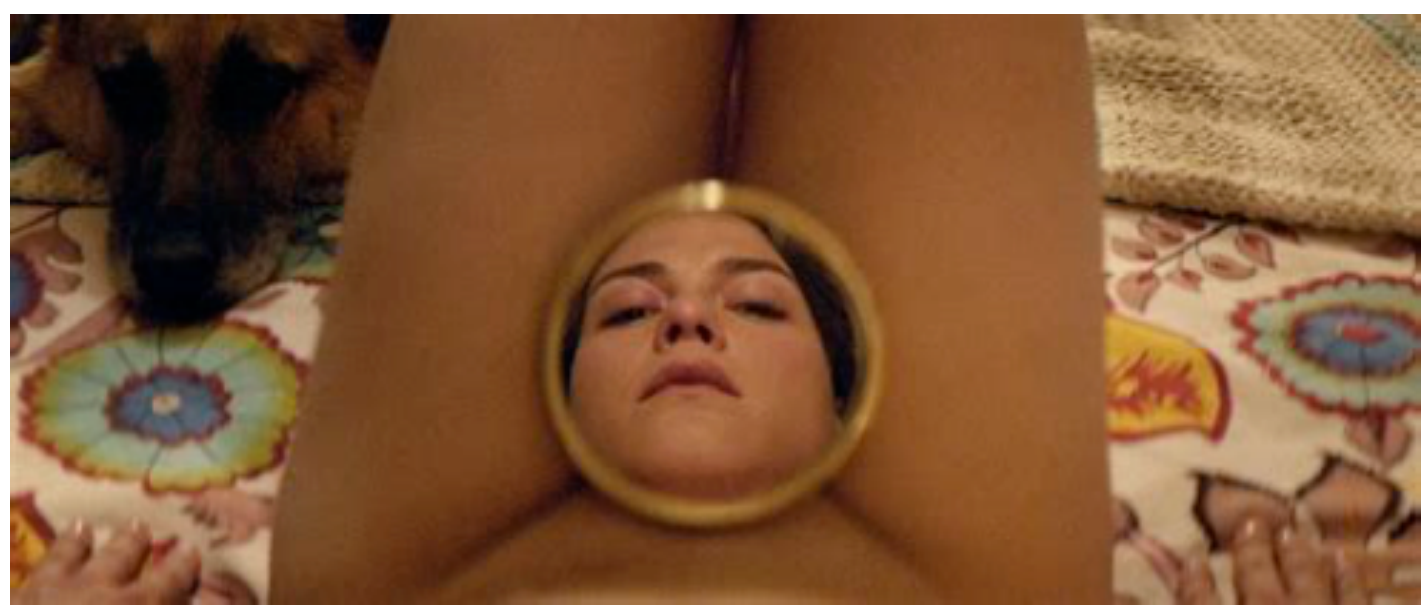

Fotograma del filme Una mujer fantástica.

Tras esta imagen, Marina se prepara y sale de su apartamento, se dirige a algún sitio que parece importante. Ya al entrar en el teatro, los grandes espejos en los que se refleja nos están adelantando algo, todas las miradas van a centrarse en ella de nuevo (Imagen 15 e Imagen 16). Seguidamente, encontramos a Marina mirando a cámara a la vez que está mirándose al espejo, aquí, ambos elementos son uno (Imagen 17). Tras ella, observamos un espejo más, y en el siguiente plano se nos descubre que hay varios espejos más rodeándola, Marina, con vestimenta y peinado de gala, se ajusta una chaqueta. En este camerino en el que se encuentra, puede verse a sí misma desde diferentes ángulos, ella puede observar aquí con mayor precisión la totalidad de su imagen. Además, esta imagen también nos dice que Marina, como apuntábamos, va a ser vista desde diferentes ojos, se antepone a ello, observa previamente cómo va a ser vista, va a ser el centro de todas las miradas, en esta ocasión no como sospechosa sino haciendo lo que más le gusta. 
Imagen 15 .

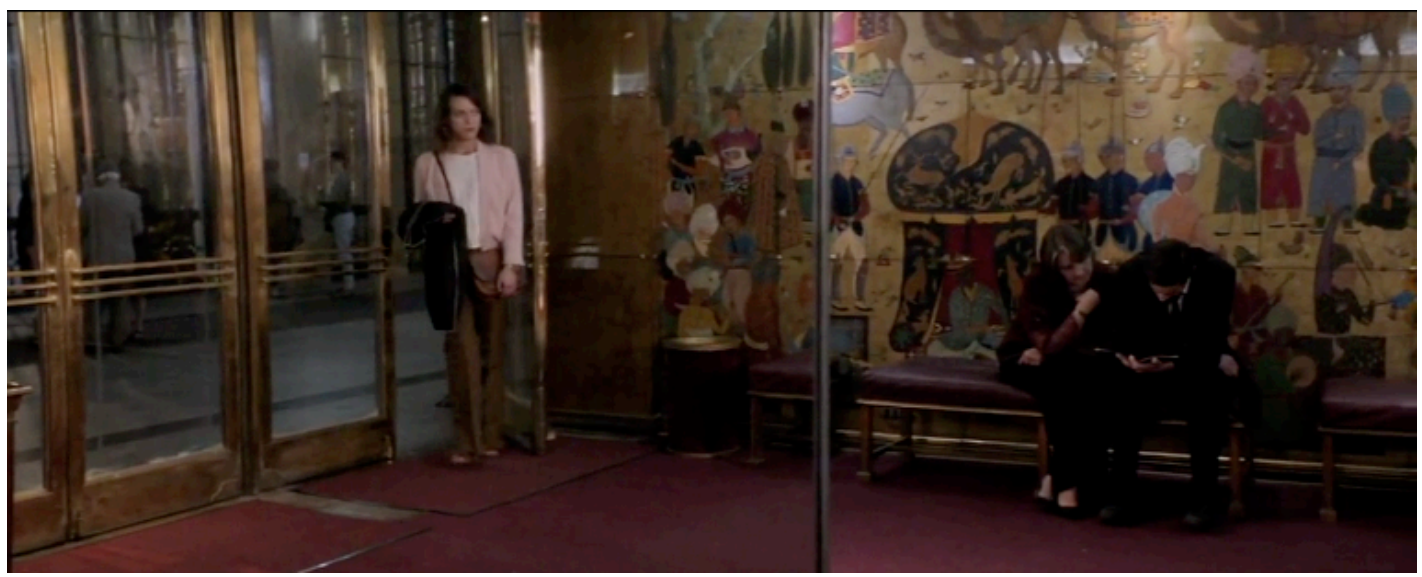

Fotograma del filme Una mujer fantástica.

Imagen 16.

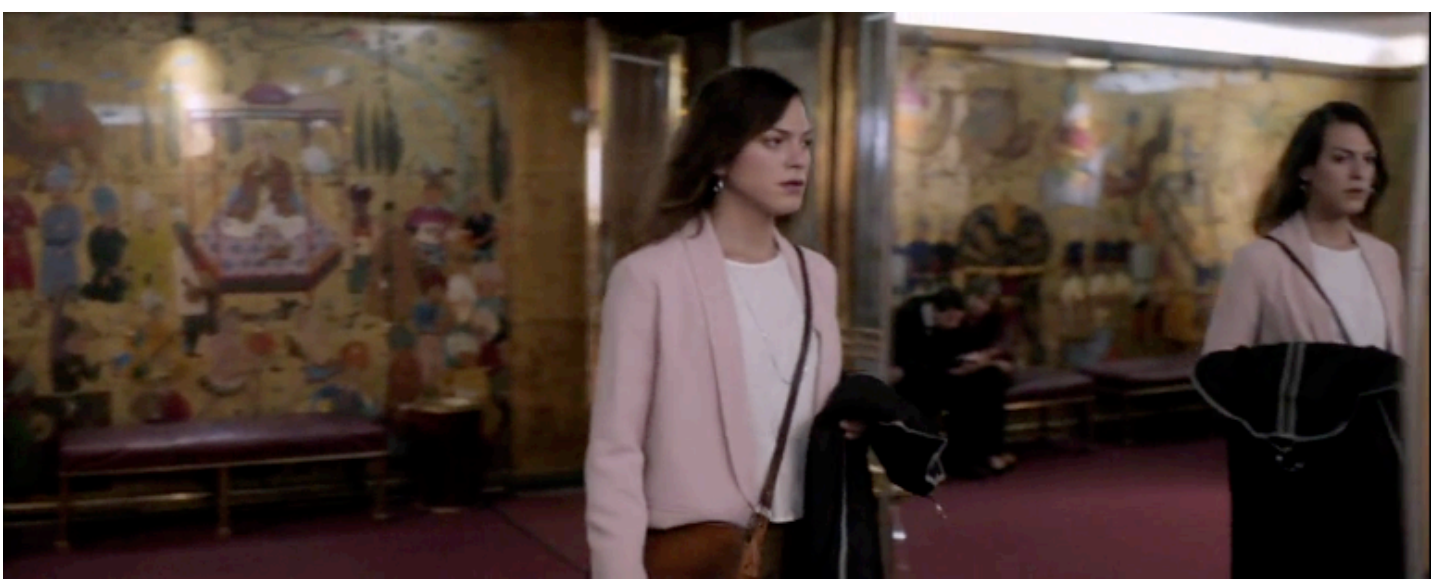

Fotograma del filme Una mujer fantástica.

Imagen 17.

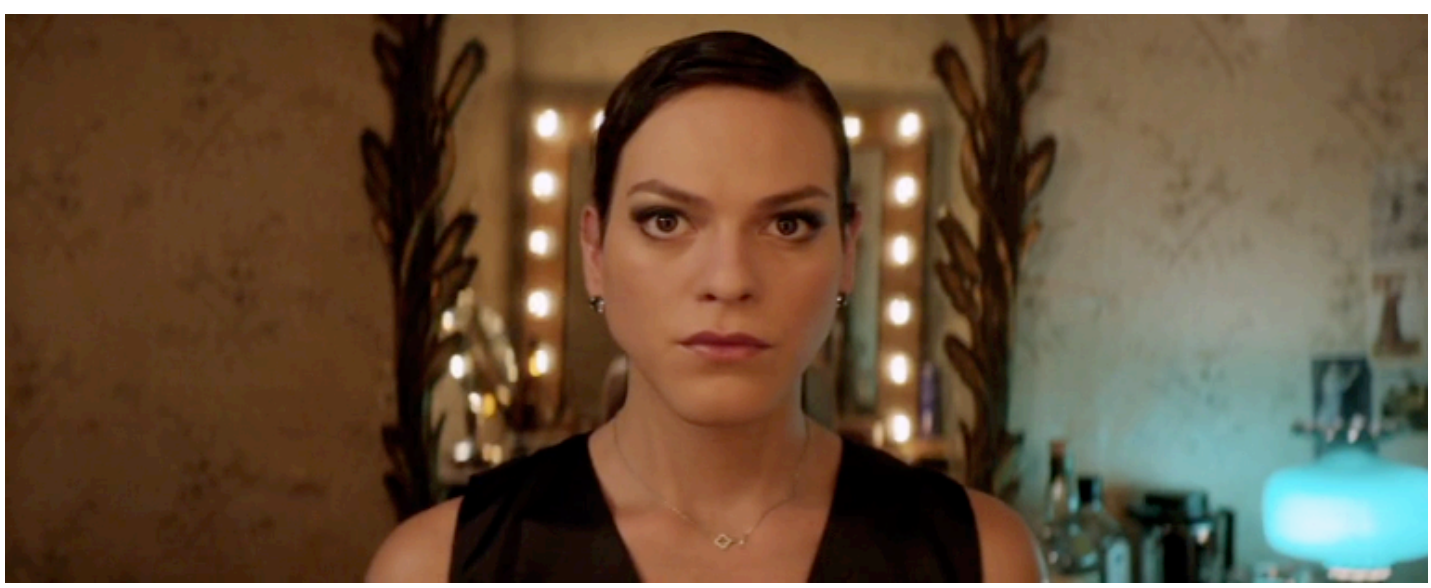

Fotograma del filme Una mujer fantástica. 
Imagen 18.

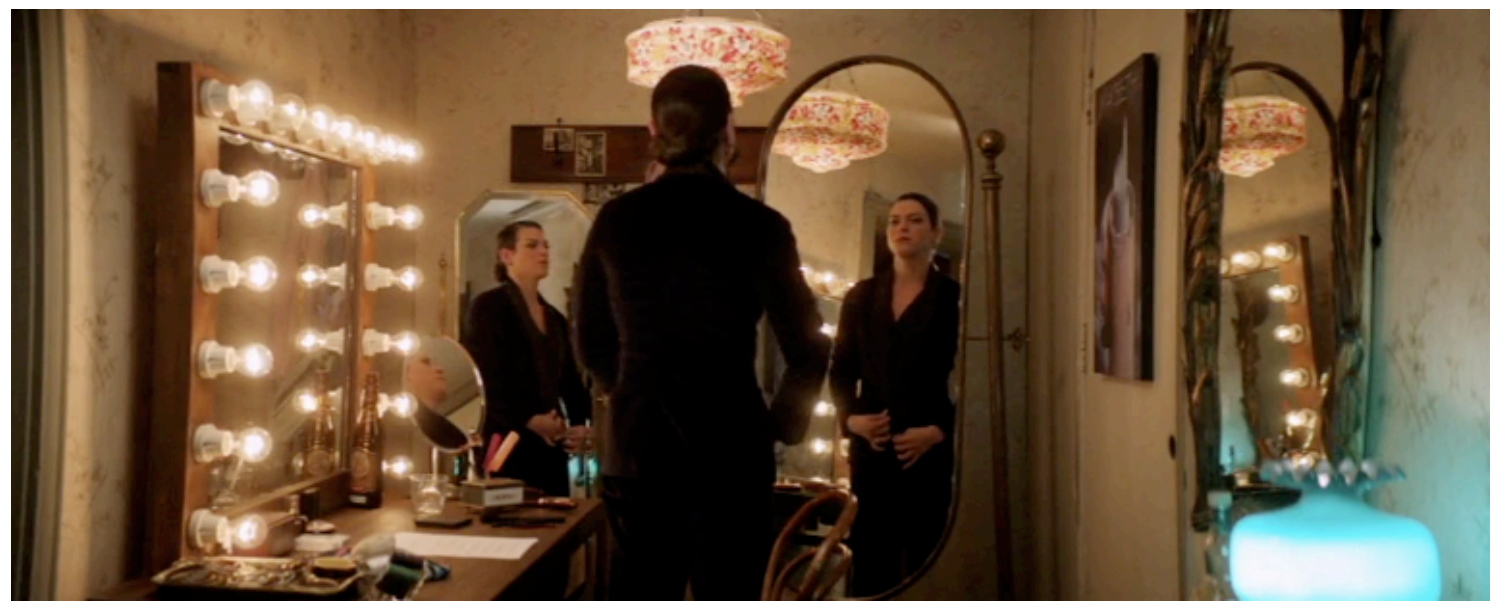

Fotograma del filme Una mujer fantástica.

\section{Conclusiones}

$\mathrm{Si}$ algo podemos afirmar es que la manera reiterada en la que se nos presentan los espejos en el filme de Sebastián Lelio no es casual y, por lo tanto, tienen intención dentro de la narración. Aunque existan algunos casos en los que no haya una aportación por parte de este reflejo a la narración a la protagonista, son múltiples los que si llevan a cabo esta función. Por lo tanto, los espejos suponen en esta obra un elemento narrativo de gran relevancia que aporta matices e información.

Por otra parte, en diversas ocasiones, la identidad de Marina se ve reforzada, cuestionada o simplemente mostrada a través de este elemento; tanto en los momentos de la trama en los que Marina es puesta en duda o sufre violencia, como en los que se reivindica como mujer y como artista. Podemos, entonces, decir que se da una relación entre el sujeto, su identidad y su imagen, tanto de cara al espectador y a la manera de narrar la historia como de manera interna de la propia protagonista para sí misma.

Además, podemos afirmar que, no sólo encontramos espejos dentro del filme, sino que podemos considerar el propio filme como un reflejo de la sociedad chilena, de la realidad a la que se enfrentan muchas personas trans en su día a día, tanto en Chile como en otras geografías. Desde la negativa de un policía a llamarla Marina y tratarla en femenino porque en su documento de identidad aún no ha podido modificarlo, hasta la insinuación de que es prostituta por parte de la mujer que investiga si sufrió violencia por parte de Orlando. Del mismo modo, los insultos y la violencia son también una muestra de lo que puede llegar a sufrir 
de manera psicológica y física una persona trans por el mero hecho de ser quien es. Pero también, en este reflejo, se destaca la fuerza, la lucha y el valor de Marina para sobreponerse a todas las situaciones de injusticia, intolerancia y odio y conseguir reafirmar su identidad y lograr su sueño, más como un deseo de cambio social que como un reflejo de la realidad.

Por último, pensamos que es relevante apuntar a la importancia que tiene la representación y visibilización de las personas trans en el cine, este colectivo, a menudo silenciado, puede encontrar en el personaje de Marina Vidal un referente, al igual que en la actriz Daniela Vega, que como veíamos, ha afirmado que este filme ha cambiado la forma de pensar de una parte de la sociedad chilena. Cabe señalar, que, además de ser la primera presentadora trans de una sección en la gala de los Oscar, ha sido elegida por Time ${ }^{7}$ como una de las 100 personas más influyentes de 2018. Esto demuestra la necesidad de contenidos y de actores y actrices que reivindiquen las identidades trans para poder promover el cambio social.

\section{Notas}

1. Traducción propia: Tú me haces sentir muy bien por dentro, y solo quiero estar cerca de ti, tú me haces sentir muy viva.

2. Borraz, Marta, "El Congreso avala sin el apoyo del PP que las personas trans cambien su sexo legal sin declararse enfermas", eldiario.es, diario digital, 30 de noviembre de 2017.

3. Borraz, Marta, "La OMS dejará de considerar la transexualidad un trastorno, pero pasará a llamarla "incongruencia de género"”, eldiario.es, diario digital, 31 de enero de 2017.

4. Borraz, Marta, "La OMS deja de considerar la transexualidad un trastorno mental", eldiario.es, diario digital, 18 de junio de 2018.

5. "Daniela Vega: "Salgo a representar a Chile con nombre masculino en mi pasaporte, ¿dónde están mis derechos?"'”, Emol, 9 de febrero de 2018.

6. Barrios P., Alondra, "Daniela Vega sobre una ley de identidad de género: "La película ya cambió una parte del pensamiento de los chilenos"', Emol, 9 de marzo de 2018.

7. "Most influential people 2018", Time (http://time.com/collection/most-influential-people2018/). 


\section{Referencias bibliográficas}

Araneta Zinkunegi, A. (2012). Diversidades cuestionadoras: la campaña internacional «Stop Trans Patologización 2012», Feminismo/s, 19; 143-163.

Bal, M. (1985). Teoría de la narrativa (una introducción a la narratología). Madrid: Cátedra. Benshoff, H.M. \& Griffin, S. (2005). Queer Images: A History of Gay and Lesbian Film in America. Rowman \& Littlefield Publishers.

Butler, J. (2007). El género en disputa. El feminismo y la subversión de la identidad. Barcelona: Paidós.

Chaparro, N. \& Estefan, S. (2011). Imágenes de la diversidad. El movimiento de liberación LGTB tras el velo del cine, Culturales, 14, vol. VII; 57-86.

Chomsky, N. (2000). El lenguaje y los problemas del conocimiento. Madrid: A. Machado Libros.

Coll-Planas, G. \& Missé, M. (2015). La identidad en disputa. Conflictos alrededor de la transexualidad. Papers, 100, 1, 35-52.

Durán Manso, V. (2016). La representación del deseo en el cine de Tennessee Williams: homosexualidad masculina frente al Código Hays, Femeris, 1; 58-73.

Escoffier, A. (2017). Ley de Identidad de Género en el Senado ¿Negar y excluir o abrirse e incluir?, Le trans, 3; 2-6. (http://otdchile.org/biblioteca/le-trans-3/) (08-07-2018).

Fausto-Sterling, A. (2006). Cuerpos sexuados. La política de género y la construcción de la sexualidad. Barcelona: Editorial Melusina.

Godoy, G.C. (2015). La Ley de Identidad de Género y la construcción de identidades trans, Quaderns de Psicologia, 3, vol. 17; 111-121.

González Requena, M. (2007). Douglas Sirk. Madrid: Cátedra.

Grant, J.M.; Mottet, L.A. \& Tanis, J. (2011). Injustice at Every Turn: a report of the National Transgender Discrimination Survey (http://www.thetaskforce.org/static html/downloads/reports/reports/ntds full.pdf) (08-072018).

Greenberg, J.A. (1999). Defining Male and Female: Intersexuality and the Collision Between Law and Biology. 41 Arizona Law Review 265 (1999). TJSL Legal Studies Research Paper Archive, 896307. Thomas Jefferson School of Law, San Diego, California.

Herrera, C. (2011). Mas allá de las etiquetas: mujeres, hombres y trans. San Isidro: Txalaparta. Juett, J.C. \& Jones, D. (2010). Coming Out to the Mainstream: New Queer Cinema in the $21^{\text {st }}$ Century. Cambridge Scholars Publishing.

Lacan, J. (2003). Escritos I y Esctrios II. Siglo XXI. 
Lamas, M. (2013). La antropología feminista y la categoría 'género', en M. Lamas (comp.), El género. La construcción cultural de la diferencia sexual. México: Programa Universitario de Estudios de Género; 97-126.

Lauretis, T. de (1992). Alicia ya no. Feminismo, semiótica, cine. Madrid: Ediciones Cátedra.

Mejía, J. \& Almanza, M. (2011) Conquistas legales no traducen ipso facto conquistas sociales. Especial referencia a los reconocimientos jurídicos de la comunidad Lgbt, Justicia Juris, 1, vol. 7; 79- 92 .

Mira, A. (2006). Cine y homosexualidad: ¿por qué no?, Archivos de la filmoteca. Revista de estudios históricos sobre la imagen, 54; 8-19.

Palencia, L. (2008). Hollywood Queer. T\&B.

Rich, R. (1992). New Queer Cinema: the director's cut. Duke University Press.

Salcedo, E. (2009). Identidad y formación. Entre Hegel y Paul Ricoeur, Ensayo y error, 36; 2954.

Schoonover, K. \& Galt, R. (2016). Queer Cinema in the World. Durham/Londres: Duke University Press.

Shrage, L.J. (2009). You've Changed: Sex Reassignment and Personal Identity. Oxford University Press.

Stam, R.; Borgoyne, R. \& Fitterman-Lewis, S. (1999). Nuevos conceptos de la teoría del cine. Estructuralismo, semiótica, narratología, psicoanálisis, intertextualidad. Barcelona: Editorial Paidós.

Transgender Europe (2018). Trans Rights Europe Map \& Index 2018 (https://tgeu.org/transrights-map-2018/)(08-07-2018).

Transgender Europe's Trans Murder Monitoring (2017). Trans Day of Remembrance 2017 (https://transrespect.org/en/tmm-update-trans-day-remembrance-2017/) (08-07-2018).

Valdés, C. (2016). Informe sobre la "Situación de las personas trans en Chile" para el comité para la Eliminación contra la Discriminación la mujer. (http://otdchile.org/biblioteca/informede-otd-chile-sobre-la-situacion-de-las-personas-trans-en-chile-para-cedaw-2016/) (08-072018).

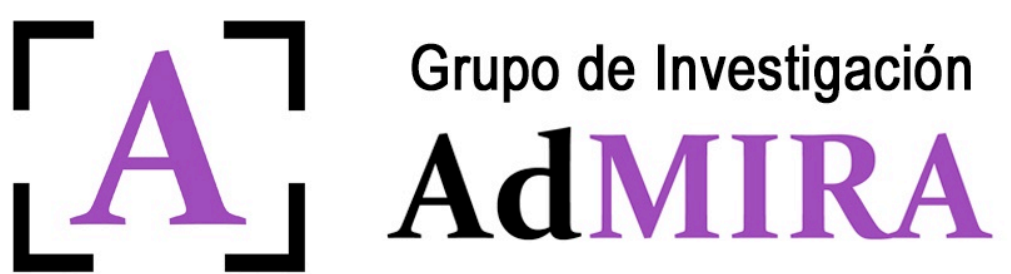

Análisis de Medios, Imágenes y Relatos Audiovisuales 